Original Research Paper

\title{
Career Cognitions among U.S. Adolescents in Military and Non-Military Families
}

\author{
Craig Morrow \\ Department of Distance Education, United States Army War College, United States
}

Article history

Received: 19-12-2018

Revised: 03-04-2019

Accepted: 11-04-2019

Email: craig.morrow@us.army.mil

\begin{abstract}
The vocation an individual engages in as an adult has several important implications for both the individual and their family and multiple factors influence their career decisions. Gender has been shown to have a significant relationship with career cognitions from childhood into adulthood. When gender is seen as a career barrier, individuals may choose a career path that suits their gender, rather than their talents. Until 2013, the U.S. military expressly prohibited women from serving in a significant percentage of key positions; this institutional sexism may make gender a more salient factor in the career cognitions of individuals developing within a military context. The actual impact of military context on career cognitions, however, has not been investigated. This ex post facto study explores the association between developmental context (military or non-military) and future-oriented career cognitions (occupational aspirations and occupational expectations) among a sample of high school students. Girls from military families were found to have higher career aspirations but their career expectations did not differ from their civilian counterparts. No differences were found among the boys. Findings of this study have practical implications for career guidance given to high school students from military families.
\end{abstract}

Keywords: Occupational Aspirations, Occupational Expectations, Gender, Military

\section{Introduction}

The vocation an individual engages in as an adult has several important implications for both the individual and their family. Marcia (1980) has suggested that vocational choices are central to identity formation (1980; Holland, 1985); perhaps more importantly, occupational choices have an obvious association with income and access to resources (e.g., education, healthcare). In early childhood, both boys and girls report aspirations that are heavily influenced by gender stereotypes; however, by age 14 individuals begin to report career aspirations more in accord with their own aptitudes (Gottfredson, 2002). Contributing to these occupational aspirations and expectations are occupational self-efficacy and outcome expectations (Lent et al., 1994; 2000). The development of occupational self-efficacy is influenced by perceived career barriers such as gender or race/ethnicity. Children, particularly girls, growing up in an environment of institutional sexism may develop differing ideas about their future careers, potentially internalizing the idea that women are less capable of serving in some occupations or of achieving the same level of success as men in certain fields.

\section{Career Cognitions}

As children develop, they become increasingly aware of the larger social context within which they exist. By the time they enter school, most children will have begun to envision themselves engaged in some vocational pursuit as an adult. Passing through adolescence and into young adulthood (age 14 and older), career cognitions are increasingly tempered by an understanding of the constraints on certain occupations. The fantasy occupations of youth (e.g., to become a movie star or professional athlete) ultimately give way to more realistic pursuits (Gottfredson, 2002; Shapiro and Crowley, 1982) which have a significant association with the individuals' actual occupations in adulthood 
(e.g., Burke and Hoelter, 1988; Clausen, 1995; Croll, 2008; Hotchkiss and Borow, 1996; Mello, 2008; Schoon et al., 2007; Schoon and Parsons, 2002; Trice and McClellan, 1993).

\section{Occupational Aspirations and Expectations}

The specific career cognitions of interest in the present study were occupational aspirations and occupational expectations. Occupational aspirations reflect "a desired career goal given ideal conditions" and occupational expectations reflect "an assessment of career possibilities when the multiple factors that may permit or preclude particular career paths are considered" (Baly, 1989, p. 255).

\section{Gender as a Career Barrier}

Several researchers have demonstrated an association between gender and occupational aspirations (e.g., Henderson et al., 1988; Mickelson, 2003; Phipps, 1995; Trice and Gilbert, 1990; Watts et al., 2015), revealing that female participants tend to have lower aspirations than their male counterparts. Traditional gender-role stereotypes likely play a role in limiting the career cognitions of American girls. Empirical research has shown that young women with more traditional gender role attitudes aspire to lower status occupations than women with more liberal gender role attitudes (O'Brien and Fassinger, 1993). Gender stereotyping has also been shown to have a stifling effect on women's academic and occupational achievement (Slater et al., 2017; Parsons et al., 1982) while studies of the association between gender role beliefs and career aspirations among men reveal little or no influence of these beliefs on men's' career cognitions (e.g., Mendez and Crawford, 2002; Morinaga et al., 1993).

\section{The Military}

The military has historically been perceived as a "masculine" pursuit. Teig and Susskind (2008) found that, of all the occupations rated by children and adults on a scale of masculinity or femininity, "Soldier" was rated more masculine than any other occupation. Until 2013, the U.S. military's Combat Exclusion Policy restricted women from serving in approximately one-third of all positions in the Army and Marine Corps (Harrell and Miller, 1997); within American society, few institutions engaged in more patent gender discrimination.

It has been suggested that the military environment promotes hypermasculinity (Mosher and Tomkins, 1988), as cited in (Turchik and Wilson, 2010). Hunter (2007), as cited in Turchik and Wilson (2010) defines hypermasculinity as extreme masculinity that includes a belief in rigidly defined gender roles. Supporting the idea of increased hypermasculinity within the military, Kurpius and Lucart (2000) found that male undergraduates at military academies or enrolled in the Reserve Officer Training Corps (ROTC) were more likely to hold traditional sex-role attitudes than their civilian counterparts (also see DeFleur et al., 1978).

Social dominance theory (Sidanius, 1993), asserts that group-based hierarchies exist in most societies and that these hierarchies advantage one or more groups and disadvantage others. Social dominance theory proposes that individuals who score high on a measure of Social Dominance Orientation (SDO; Pratto et al., 1994) are more likely to believe these hierarchical relations are justified and that some groups should be advantaged. Nicol et al. (2007), offer longitudinal data showing that SDO scores among undergraduates enrolled in a military academy increased during the four year program although the scores of their counterparts at a civilian institution remained stable. The existing research suggests the military environment promotes a greater degree of SDO and, by extension, more sexist beliefs.

\section{Children in Military Families}

Research going back more than half a century has shown military children differ from their counterparts in civilian families in the academic and occupational domains. A 1967 study of military children living in Germany (Kenny, 1967) found that military children had a higher median Intelligence Quotient (IQ) than their civilian counterparts. Two decades later, Watanabe (1985) reported that military children, relative to civilian peers, scored higher on a Vocational-Educational Goals scale. Consistent with Watanabe's findings about academic goals, individuals reared in military families are also more likely to have a college degree as adults than their civilian counterparts (Williams and Mariglia, 2002). More recent research continues to show the academic performance of military children exceeding the level of their civilian peers (for example, Esqueda et al., 2012). Given the obvious association between educational and occupational aspirations, it is reasonable to assume that children reared in a military context are likely to have higher occupational aspirations than their peers raised outside of the military. However, the possibility exists that the patent barrier to the entry of women into certain military careers presented by the Combat Exclusion Policy may increase the perception of gender as a career barrier among girls reared in Army families. This notion is supported by findings from a survey of adults who, as children, had been reared in a military context (Ender, 2002). When asked why they chose not to join the military, the second most common response, after a general lack of interest -- 
and representing $16.9 \%$ of the mixed-sex sample-was, in essence, "because I am female."

In considering the potential impact of parental attitudes on the attitudes of their children, research by Duriez and Soenens (2009) suggests that Social Dominance Orientation may be transmitted intergenerationally. In examining racist beliefs among a sample of adolescents and their parents, Duriez and Soenens (2009) found significant concordance in racist views and that this similarity could largely be explained by the intergenerational transmission of ideology as assessed by SDO and Right Wing Authoritarianism, characterized by a high degree of submissiveness to authority, a general aggressiveness directed against deviants and outgroups and a high degree of adherence to traditions and social norms (Altemeyer, 1981). Research has also shown evidence for the intergenerational transmission of gender role beliefs (Dhar et al., 2018). The intergenerational transmission of sexist beliefs and traditional sex role attitudes within the military context is also likely to have a negative influence on the career cognitions of girls reared in this environment.

Previous research has also suggested a more direct link between parental attitudes and the occupational expectations of their offspring. Parents' gender stereotypes influence their perceptions of the children's abilities and these parental perceptions subsequently influence the children's own perceptions of their abilities (Lawson et al., 2015; Jacobs, 1991; Jacobs and Eccles, 1992). Given the link between parental gender stereotypes and children's perceived abilities, it is likely that parents' gender role attitudes affect their children's gender beliefs and occupational expectations. In an empirical study of the relationship between parental attitudes and the careers of their offspring, Jacobs and her colleagues found that parents' beliefs, reported when their children were adolescents, were associated with their children's occupational choices in young adulthood (Chhin et al., 2008).

Until 2013, the U.S. military followed an overtly sexist policy; precluding women from serving in many of the core jobs in the military, especially within the Army and Marine Corps (Roulo, 2013). Children reared in in this environment may have perceived occupational supports or barriers that differed from those of similar children reared outside of a military context. Previous research has demonstrated that individuals' future-oriented career cognitions during childhood and adolescence have a significant association with the occupations individuals engage in as adults (Burke and Hoelter, 1988; Trice and McClellan, 1993). This association makes the study of career cognitions during childhood and adolescence an important area for researchers.
In sum, the military context is associated with more traditional gender role attitudes and SDO appears to be fostered within a military context and there is the potential for intergenerational transfer of these attitudes and beliefs. Taken together it appears that the military environment has significant potential to negatively influence the career cognitions of girls reared in this context. Despite the significant research examining the multiple influences on adolescents' future-oriented career cognitions, to date there have been few studies of children reared in a military context.

\section{Hypotheses}

The purpose of this study was to explore the association between developmental context and future-oriented career cognitions among a sample of high school students in the United States. This study tested two hypotheses: (1) occupational aspirations among children reared in a military context are higher than those of children reared outside of a military context and (2) occupational expectations of girls reared in a military context are lower than among girls reared outside of a military context.

\section{Method}

This study employed an ex-post facto research design (Lammers and Badia, 2005) using pre-existing groups (military, non-military) to examine group differences in occupational aspirations and expectations. This non-experimental design compares two groups exposed to different conditions but differs from an experiment in that it uses existing groups rather than random assignment. This design allowed the researcher to ascertain the association between developmental context and future-oriented career cognitions, fulfilling the purpose of this study.

\section{Participants}

A total of 152 high school students and parents (76 each; one parent per student participant) were recruited from four schools in U.S. communities with large military populations. Research shows that between sixth and eighth grade, girls are still switching their occupational preferences from stereotypically feminine roles and adopting a preference for more masculine (and higher status) jobs (Helwig, 2008). Earlier research by Helwig (2001) also found that through eighth grade, almost half of the boys and one-fifth of the girls still aspired to "fantasy" jobs. Similarly, a study of children aged 8 to 12-years, found no association between anticipated vocation, perceived capabilities, or interests (Primé et al., 2010). Other research has shown that 
occupational aspirations remain relatively stable from eighth grade through high school (Furlong and Biggart, 1999; Rojewski and Yang, 1997). These findings suggest that children in the ninth-grade (or older) would provide the most meaningful population for the proposed study.

Recruiting military and non-military students from the same schools addressed some of the potential confounds in this study because these children share significant similarity in school-level influences and other local environmental factors; for example, sampling families residing in the same school catchment area likely increased homogeneity of Socioeconomic Status (SES) within the sample.

\section{Materials}

\section{Occupational Aspirations and Expectations}

The dependent variables for this study were the occupational aspirations and occupational expectations of the adolescents. Students were asked to identify three jobs they hoped to attain (aspirations) and three jobs they expected to attain (expectations) (Perry et al., 2009). Parents were asked the same questions regarding the aspirations and expectations they held for the student. Following data collection, a numerical value was assigned to these aspirational and expected careers, based on the Nakao-Treas Socioeconomic Index (Nakao and Treas, 1990), to indicate the relative level of occupational prestige. The Socioeconomic Index (SEI) scores for each of the three responses on the measures of occupational aspirations and occupational expectations were averaged for use in the analyses.

Like most measures of occupational status, the Nakao-Treas Socioeconomic Index does not provide SEI scores for unpaid labor (e.g., homemaker), or for the military. Because the extant socioeconomic indices typically do not provide an SEI for the military, other researchers have coded military careers the same as "Protective Services" (Rojewski, 1997) or "lower working class" (Willick et al., 1975). Ganzeboom and Treiman (2003) took a more nuanced approach, creating three distinct categories of personnel within the military: "ordinary" Soldiers, noncommissioned officers and commissioned officers. Like Rojewski (1997), Ganzeboom and Treiman (2003) equated ordinary Soldiers with protective service workers. Noncommissioned officers were equated with "Police Inspectors and Detectives" and commissioned officers were equated with corporate managers of large enterprises. The Nakao-Treas SEI scores for these equivalent occupations are 48.90 for lower-enlisted members, 63.20 for noncommissioned officers and 68.06 for commissioned officers. All respondents indicating "military" as a career aspiration or expectation were scored as 63.20 (noncommissioned officer), unless they explicitly specified an aspiration or expectation of becoming a commissioned officer (e.g., "military officer," "General," "Colonel," Admiral," "commander").

A survey by Nilson (1978) found that men and women rated the occupational prestige of "housewife" equivalent to that of a bookkeeper. Interestingly, a much more recent study (Goyder et al., 2003) also found that the occupational prestige for a "stay-athome spouse" was comparable to that of a bookkeeper. Therefore, respondents who aspired (or expected) to become homemakers were assigned a prestige score corresponding to the Nakao-Treas SEI score for a bookkeeper (37.95).

\section{Context (Military or Non-Military)}

The principal variable of interest was the developmental context of the adolescent (military or non-military). This variable was assessed by asking parents to indicate if either of the adolescent's parents was in the military. The parent questionnaire also collected information concerning branch of service (i.e., Army, Navy, Air Force, Marine Corps), rank and length of military service.

\section{Demographics}

In addition to the data collected on occupational aspirations and expectations, students were asked to self-report their racial/ethnic background, overall grade point average and the grades they usually receive in core subjects (i.e., math, English, science, social studies). The parent questionnaire collected information on household income, parental education levels, family structure, race/ethnicity, military affiliation and parental aspirations and expectations for their child.

All participants (students and parents) selfreported their racial/ethnic background through a free response question asking them to "Please list the racial/ethnic group (or groups) that best describe you." Responses were coded into three categories (Black, White, Hispanic) based on those used by the US Census bureau. A fourth category ("other") was also created; composed of the five responses with very small representation in the sample $(n \leq 4)$, these included the following: "Asian," "Filipino," "Good," "Native American," and "Other."

Academic performance was assessed by asking students to self-report their overall grade point average as well as the grades they usually receive in four core subjects (English, math, science and social studies). Previous research with college undergraduates has shown a significant correlation $(\mathrm{r}=0.97, \mathrm{p}<0.0001)$ between self-reported Grade Point Average (GPA) and the GPA obtained from school records (Cassady, 2001). Research with high school students (Dornbusch et al., 
1987) also found a strong correlation $(\mathrm{r}=0.80)$ between self-reported grades and academic records. In this study, eleven students did not report their GPA, but all students provided information about letter grades received. Because of the significant correlation between GPA and reported grades in core subjects $(r=0.84$, $\mathrm{p}<0.001$ ) and the greater amount of missing data for GPA, the letter grades received in core subjects were averaged to create the academic performance variable used in all analyses.

To assess SES, parents were asked to indicate the appropriate range of total monthly household income from a five point scale: $1=\$ 2000$ per month or less; 2 $=\$ 2001$ to $\$ 4000 ; 3=\$ 4001$ to $\$ 6000 ; 4=\$ 6001$ to $\$ 8000 ; 5=$ More than $\$ 8000$ per month. The parent questionnaire also asked parents to indicate the highest level of schooling completed from seven options spanning the range from "Less than high school" to "graduate or professional degree." Parental education and income data were converted to $\mathrm{Z}$-scores and aggregated into a single SES score.

Family structure was also surveyed. In a study of the career aspirations of elementary school children, Trice et al. (1995), as cited in Whiston and Keller (2004) found that children living in family situations other than two-parent homes were substantially more likely to express no occupational aspirations than were children in two-parent homes. McCullough et al. (1994) found that students who aspired to more prestigious careers were also more likely to be living with two biological parents. In examining occupational outcomes in young adulthood, Sun and $\mathrm{Li}$ (2008) found that at age 26, individuals who had been raised by divorced single-parents or in stepfamilies had lower earnings and less prestigious occupations than individuals from traditional families. To capture the family structure of participants in the present study, the parent questionnaire asked the adult respondent "Who lives in the same house with the student most of the time? (Circle all that apply)." Responses were selected from the following twelve items: Mother, Father, Stepmother, Stepfather, Brother, Sister, Other adult male relative, Other adult female relative, Unrelated adult male, Unrelated adult female. Brother and sister were included in the list to ensure adult siblings were not reported as "Other adult female/male relative." With the exception of adolescents living without an adult in the home (e.g., emancipated minors), this list is exhaustive without being needlessly intrusive. The parent questionnaire also asked the adult respondent to specify her or his relationship to the student. Families were coded into five categories: traditional, stepfamily, single-parent, cohabiting, or other (e.g., students living with grandparents). There were no cases suggesting that a student was living independently.
Of all the measures used in this study, only one question (students' Grade Point Average) elicited a response rate below $90 \%$. The low rate of itemnonresponse from the initial data collection effort suggests the surveys were appropriately designed for the target population.

\section{Procedure}

This study employed an ex-post facto research design (Lammers and Badia, 2005) using pre-existing groups (military, non-military) to examine group differences in occupational aspirations and expectations. This nonexperimental design compares two groups exposed to different conditions but differs from an experiment in that it uses existing groups rather than random assignment.

Data collection took place in two waves during the academic year. Surveys were distributed in person to students in their schools. Homeroom teachers read a brief statement describing the study and asking for volunteers. Teachers then provided the study materials to any volunteers. The survey packet distributed to participants included a cover letter, the student survey, parent survey, consent forms and a business reply envelope. All materials were completed in the home and returned via business reply envelopes. Parents were required to indicate their willingness to allow their child to participate by signing an informed consent form. Adolescent participants also indicated their assent to participation by signing the same informed consent form. In the first wave of data collection, participants completing and returning the questionnaires and consent form received a \$10 gift card from a major retailer. For the second round of data collection, the envelope with the study materials included a pre-paid incentive (\$2 cash).

The survey produced a total sample of 152 participants (76 adult-adolescent pairs). The exact response rate cannot be calculated because the number of students (and parents) who actually received the study materials from their teacher is unknown. Data were collected in two waves; analyses of the two waves revealed no differences between early and late responders. Student assent and parental consent were obtained for all participants.

\section{Results}

In an effort to provide a comprehensive description of the data available and avoid dismissing meaningful results that may have failed to achieve statistical significance (Type II error), effect sizes are provided for results that are statistically non-significant as well as those that are statistically significant. Authors in the field of psychology (e.g., Thompson, 1999; 2007) and elsewhere (e.g., Levine and Hullett, 2002; Nakagawa and Cuthill, 2007) have urged that effect 
sizes be reported for non-significant as well as significant findings. For most of the analyses, the partial-eta-squared $\left(\eta^{2} p\right)$ was used as the principal measure of effect size. A value of $\eta^{2} p$ greater than 0.01 is considered a small effect, a value greater than 0.059 is considered a medium sized effect and a value greater than 0.138 is considered a large effect (Cohen, 1988).

\section{Survey Nonresponse Analysis}

To examine nonresponse bias, the characteristics of early respondents were compared with those of late respondents (Israel, 1992). For the categorical variables, Pearson's chi-squared tests were used; for the continuous variables, analyses of variance (ANOVA) was used. Because multiple tests were performed, a Bonferroni correction was applied to correct for type I error. Analysis of the categorical variables revealed no differences between early and late responders with regard to family structure, $\chi^{2}(4, \mathrm{~N}=76)$ $=1.12, \mathrm{p}=0.89$, sex of the adolescent, $\chi^{2}(1, \mathrm{~N}=75)=$ $0.58, \mathrm{p}=0.45$, developmental context, $\chi^{2}(1, \mathrm{~N}=76)=$ $1.07, \mathrm{p}=0.30$ or ethnicity, $\chi^{2}(3, \mathrm{~N}=71)=1.78, \mathrm{p}=$ 0.62. Similarly, the ANOVA for the continuous variables also found no significant differences between early and late responders; Table 1.

\section{Demographic Analysis}

Although race/ethnicity, family structure, SES and school performance were not central to the questions this study sought to answer, they have each demonstrated an association with the variables of interest; hence, they must be considered in the design of the study. The ANOVA revealed that the grades received in school were not significantly different between the military and non-military populations, $\mathrm{F}(1,74)=0.54, \mathrm{p}=0.47$. Socioeconomic status was also not significantly different between the military and non-military populations $\mathrm{F}(1,65)=2.30, \mathrm{p}=0.13$. The distribution of racial/ethnic categories was also not significantly different between military and non-military populations, $\chi^{2}(3, \mathrm{~N}=74)=2.74, \mathrm{p}=0.43$. Family structure did achieve significance at the Bonferronicorrected level of significance, $\chi^{2}(4, \mathrm{~N}=76)=19.17$, $\mathrm{p}<0.001$, with military households more likely to report a traditional family structure. The results of these initial analyses show that, with the exception of family structure, the two groups do not differ significantly on the measured variables. To control for the effects of family structure, this variable was included as a between-subjects factor in subsequent ANOVA models. Academic achievement was retained as a covariate because it was found to be significantly correlated with both occupational aspirations $(r=0.39$, $\mathrm{p}<0.001)$ and expectations $(\mathrm{r}=0.44, \mathrm{p}<0.001)$, but was not associated with developmental context.

\section{Analysis of Variables of Interest}

The first hypothesis proposed that occupational aspirations among children reared in a military context would be higher than those of children reared outside of a military context. Analysis of covariance (ANCOVA), with occupational aspirations as the dependent variable, developmental context, sex of the adolescent and family structure as the between-subject factors and academic performance as a covariate was used to test this hypothesis. Subsequent to the ANCOVA, a planned comparison was performed to determine if military girls had higher aspirations than their civilian counterparts; a similar comparison was also made for the boys.

The analysis found a nonsignificant association between military context and increased occupational aspirations, $\mathrm{F}(1,67)=1.60, \mathrm{p}=0.21, \eta^{2} \mathrm{p}=0.02$. Female respondents had slightly lower aspirations compared to male respondents, $\mathrm{F}(1,67)=1.02, \mathrm{p}=$ $0.32, \eta^{2} \mathrm{p}=0.02$, but again this difference was not significant. The interaction of military context with sex of the adolescent was also nonsignificant, $F(1,67)$ $=1.10, p=0.31, \eta^{2} p=0.02$, but suggested the possibility that the influence of military context on occupational aspirations may have a greater association with higher aspirations among girls from military families than among the boys. Figure 1 provides a graphic representation of the mean occupational aspirations of boys and girls from military and non-military families, after controlling for family structure and academic achievement. The graph suggests that any group difference in aspirations is likely being driven by the higher career aspirations among girls reared in military families relative to their civilian peers; this is also supported by the smallsized effects found for developmental context and the interaction of developmental context with sex in predicting occupational aspirations.

Post hoc analysis revealed, consistent with hypothesis one, that girls from military families did have higher aspirations than their counterparts from civilian families, $F(1,71)=4.97, p=0.03$. The same was not the case for the boys, $\mathrm{F}(1,71)=0.00, \mathrm{p}=$ 0.95. The estimated marginal means for each group, controlling for family structure and academic achievement, are shown in Table 2.

The second hypothesis proposed that occupational expectations of girls reared in a military context would be lower than among girls reared outside of a military context. The ANCOVA suggested developmental context (military versus non-military) was not significantly associated with differences in occupational expectations, $\mathrm{F}(1,67)=0.28, \mathrm{p}=0.60$. The main effect of sex also failed to achieve statistical significance and showed no effect, $F(1,67)=0.57, p$ $=0.46$. Similarly, there was no interaction between sex and group, $F(1,67)=0.25, \mathrm{p}=0.62$, see Fig. 2 . 
Craig Morrow / Current Research in Psychology 2018, Volume 8: 1.12 DOI: 10.3844/crpsp.2018.1.12

Table 1: Comparison of early and late responders

\begin{tabular}{|c|c|c|c|c|c|c|c|}
\hline Variable & Data Collected & Mean & S.D. & $\mathrm{N}$ & $\mathrm{F}$ & $\mathrm{df}_{1}, \mathrm{df}_{2}$ & $\mathrm{p}$ value \\
\hline \multirow[t]{2}{*}{ Socioeconomic Status } & First wave & -0.06 & 2.64 & 59 & 0.36 & 1,74 & 0.55 \\
\hline & Second wave & 0.51 & 0.63 & 8 & & & \\
\hline \multirow[t]{2}{*}{ Age } & First wave & 15.63 & 0.69 & 58 & 1.41 & 1,72 & 0.23 \\
\hline & Second wave & 15.34 & 0.44 & 7 & & & \\
\hline \multirow[t]{2}{*}{ Grade Point Average } & First wave & 3.35 & 0.65 & 67 & 1.01 & 1,62 & 0.32 \\
\hline & Second wave & 3.60 & 0.40 & 8 & & & \\
\hline \multirow[t]{2}{*}{ Occupational Aspirations } & First wave & 71.05 & 13.62 & 68 & 2.59 & 1,73 & 0.11 \\
\hline & Second wave & 62.27 & 14.66 & 8 & & & \\
\hline \multirow[t]{2}{*}{ Occupational Expectations } & First wave & 64.47 & 14.78 & 68 & 0.47 & 1,73 & 0.50 \\
\hline & Second wave & 60.76 & 11.39 & 8 & & & \\
\hline
\end{tabular}

Table 2: Group Means for Occupational Aspirations and Expectations

\begin{tabular}{|c|c|c|c|c|c|c|}
\hline \multirow[b]{2}{*}{ Dependent Variable } & \multirow[b]{2}{*}{$\begin{array}{l}\text { Developmental } \\
\text { Context }\end{array}$} & \multirow[b]{2}{*}{$\begin{array}{l}\text { Sex of } \\
\text { Adolescent }\end{array}$} & \multirow[b]{2}{*}{ Mean } & \multirow[b]{2}{*}{$\begin{array}{l}\text { Standard } \\
\text { Error }\end{array}$} & \multicolumn{2}{|c|}{ 95\% Confidence Interval } \\
\hline & & & & & Lower Bound & Upper Bound \\
\hline \multirow[t]{4}{*}{ Occupational Aspirations } & Civilian & Female & 62.41 & 3.35 & 55.74 & 69.09 \\
\hline & & Male & 69.05 & 4.23 & 60.60 & 77.50 \\
\hline & Military & Female & 70.07 & 3.74 & 62.6 & 77.54 \\
\hline & & Male & 70.12 & 4.55 & 61.04 & 79.20 \\
\hline \multirow[t]{4}{*}{ Occupational Expectations } & Civilian & Female & 58.61 & 3.43 & 51.78 & 65.45 \\
\hline & & Male & 57.69 & 4.33 & 49.04 & 66.34 \\
\hline & Military & Female & 58.38 & 3.83 & 50.73 & 66.03 \\
\hline & & Male & 54.20 & 4.66 & 44.90 & 63.49 \\
\hline
\end{tabular}

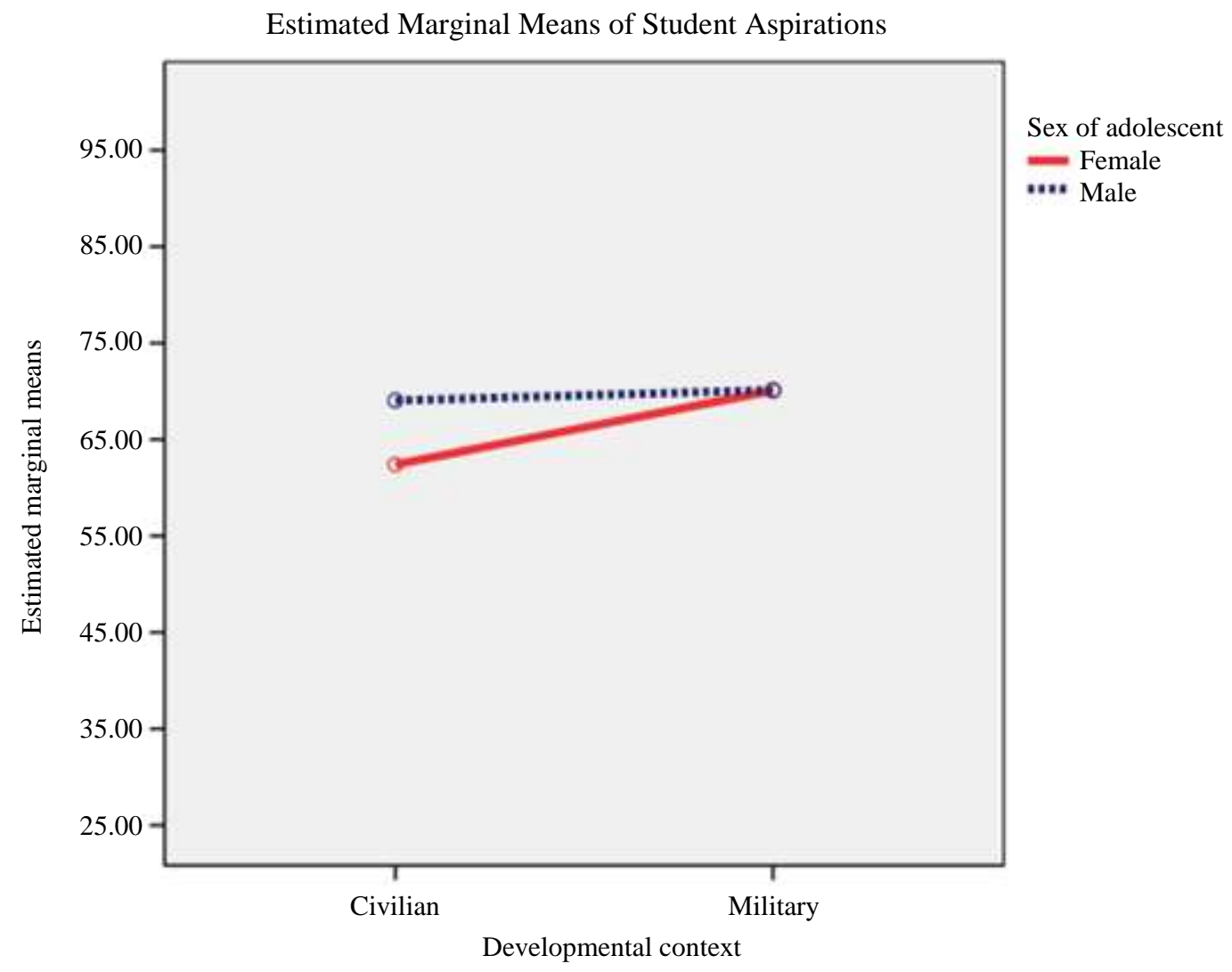

Covariates appearing in the model are evaluated at the followung values: Acadenic performance $=2.9039$

Fig. 1: Occupational aspirations by group and sex 


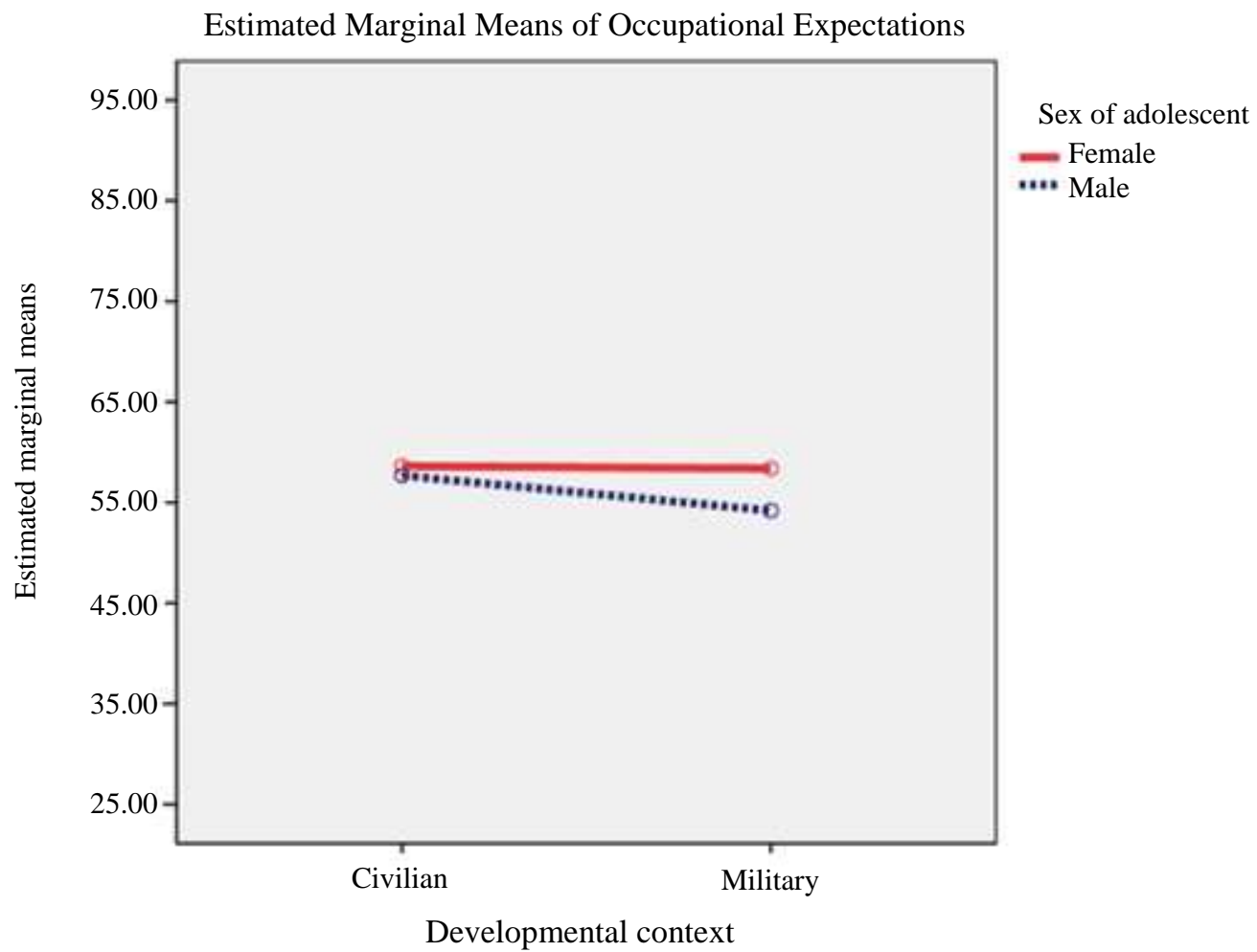

Covariates appearing in the model are evaluated at the followung values: Acadenic performance $=2.9039$

Fig. 2: Occupational expectations by group and sex

Given the finding that girls from military families had significantly higher occupational aspirations than their civilian peers, but were no different in terms of occupational expectations, additional test was conducted to determine if the gap between aspirations and expectations was significantly different between these groups. ANCOVA, controlling for academic performance, revealed that the larger gap between occupational aspirations and expectations for military girls was marginally significant with a medium effect size, $F(1,44)=3.76, p=0.059, \eta^{2} p=0.08$. Similar analysis for the boys revealed no difference between the two groups, $\mathrm{F}(1,26)=0.13, \mathrm{p}=0.73, \eta^{2} \mathrm{p}=0.01$.

\section{Discussion}

As hypothesized, the military children in this sample had higher mean levels of occupational aspirations than their civilian counterparts. Subsequent analysis revealed that aspirations among the girls were significantly different between contexts (with girls from military families having significantly higher aspirations); aspirations among the boys were not significantly different between contexts. It therefore appears likely that being reared in a military context has a positive influence on the occupational aspirations of military children, but that this context effect is more pronounced among girls.

Unlike occupational aspirations, occupational expectations are subject to the influence of perceived career barriers (Lent et al., 2000); hence, the occupational expectations of girls reared in a military context were hypothesized to be lower than their civilian peers as a result of the overt institutional sexism present in the military context. This hypothesis was partially supported in that the higher aspirations of girls reared in military families were not associated with similarly elevated levels of occupational expectations. It is concerning that the higher aspirations of girls reared in military families do not appear to translate into higher occupational expectations. Despite the association between aspirations and expectations empirically demonstrated in this study $(\mathrm{r}=0.65$, p>0.001) and other works (e.g., Patton and Creed, 2007; $\mathrm{r}=0.69, \mathrm{p}>0.001$ ), it appears that some factor present in the military context may be suppressing the occupational expectations of girls in military families.

Although this study concluded before the U.S. military began to allow women to serve in all combat jobs, a replication is likely to produce similar results. Although women are now permitted to serve as infantry and armor officers, the number doing so remains trivial. In the five years since the repeal of the 
Combat Exclusion Policy, only 70 women have completed the training to become infantry or armor officers (Swick and Moore, 2018). This represents less than one-tenth of one percent of the number of officers in the U.S. Army (Department of the Army, 2017). Even though the U.S. military continues on a path to becoming more gender egalitarian, the impact of two centuries of institutional sexism are likely to linger for many years (see Trobaugh, 2018); this lingering sexism is likely to continue to impact both those in uniform and their family members.

This research furthers the understanding of how the future-oriented career cognitions of high school students are impacted by their developmental context. Despite having higher occupational aspirations, the overall mean levels of occupational expectations among military girls were no higher those of the civilian girls. This greater aspiration-expectation gap among young women reared in military families may represent "lost talent" among this population (Hanson, 1994). This lost talent can have significant financial implications for both the individual and for the larger society as young women who may have made great contributions from positions of power are instead focused on lower status and/or more traditionally feminine career paths. These findings support the need to modify career counseling programs to make these services more effective. This research suggests a constructivist approach to career counselling may be particularly important in counselling young girls from military families (McMahon, 2016). Given the possibility that adolescents reared in military contexts (particularly girls) may have foreclosed on some viable career options (Brown and Lent, 1996, or may misperceive the career options available to them (Baxter, 2017), career counselors need to evaluate this possibility using existing tools). There may also be cause for parents and counselors to seek career mentors for girls from military families, as career mentors have been shown to produce a closer match between their aspirations and expectations among adolescent girls from disadvantaged groups (Hellenga et al., 2002).

\section{Acknowledgement}

This research was supported in part by a grant from the Linda Brodsky Strumpf Liberal Arts Centennial Graduate Endowment of the Pennsylvania State University. This research was conducted as part of a doctoral dissertation by the author, under the supervision of Dr. Lynn S. Liben.

\section{Author's Contributions}

Craig Morrow reviewed the literature, conceived the research idea, designed the study, led data collection, analyzed the data, and compiled the manuscript. The views expressed here are the author's own and do not represent the positions of the Department of Defense, United States Army, or any government agency.

\section{Ethics}

This study was carried out by the researcher based on the approval of an Institutional Review Board and the various schools where data collection was conducted.

\section{References}

Altemeyer, R.A., 1981. Right-wing authoritarianism. Winnipeg: University of Manitoba Press.

Baly, I., 1989. Career and Vocational Development of Black Youth. In: Black Adolescents, Jones, R.L. (Ed.), CA: Cobb and Henry, Berkeley, pp: 249-265.

Baxter, J., 2017. The career aspirations of young adolescent boys and girls. In: Australian Institute of Family Studies, The Longitudinal Study of Australian Children Annual Statistical Report, Melbourne: Australian Institute of Family Studies.

Brown, S. and R. Lent, 1996. A social cognitive framework for career choice counseling. Career Develop. Quarterly, 44: 355-367.

Burke, P.J. and J.W. Hoelter, 1988. Identity and sex-race differences in educational and occupational aspirations formation. Soc. Sci. Res., 17: 29-47.

Cassady, J.C., 2001. Self-reported GPA and SAT: A methodological note. Practical Assess. Res. Evaluat.

Chhin, C.S., M.M. Bleeker and J.E. Jacobs, 2008. Gender-Typed Occupational Choices: The LongTerm Impact of Parents' Beliefs and Expectations. In: Gender and Occupational Outcomes: Longitudinal Assessments of Individual, Social and Cultural Influences, Watt, H.M.G. and J.S. Eccles (Eds.), American Psychological Association, Washington, D.C., pp: 215-234.

Clausen, J.A., 1995. Gender, contexts and turning points in adults' lives. In: Examining lives in context: Perspectives on the Ecology of Human Development, Moen, P., G.H. E. Jr and K. Luscher (Eds.), American Psychological Association, Washington, D.C., pp: 365-389.

Cohen, J., 1988. Statistical Power Analysis for the Behavioral Sciences, 2nd Edn., Routledge, ISBN10: 1134742770, pp: 567.

Croll, P., 2008. Occupational choice, socio-economic status and educational attainment a study of the occupational choices and destinations of young people in the British Household Panel Survey. Res. Papers Educat., 23: 243-268.

DeFleur, L.B., D. Gillman and W. Marshak, 1978. Sex integration of the U.S. Air Force Academy: Changing roles for women. Armed Forces Soc., 4: 607-622.

Department of the Army, 2017. Army Demographics: FY17 Army Profile. Department of the Army (Strength Analysis and Forecasting Division). 
Dhar, D., T. Jain and S. Jayachandran, 2018. Intergenerational transmission of gender attitudes: Evidence from India. J. Develop. Stud.

Dornbusch, S., P. Ritter, P. Leiderman, D. Roberts and M. Fraleigh, 1987. The relation of parenting style to adolescent school performance. Child Develop., 58: 1244-1257.

Duriez, B. and B. Soenens, 2009. The intergenerational transmission of racism: The role of right-wing authoritarianism and social dominance orientation. J. Res. Personality, 43: 906-909.

Ender, M.G., 2002. Military Brats and Other Global Nomads: Growing Up in Organization Families. 1st Edn., London: Praeger.

Esqueda, M., R. Astor and K. De Pedro, 2012. A call to duty: Educational policy and school reform addressing the needs of children from military families. Educat. Res., 41: 65-70.

Furlong, A. and A. Biggart, 1999. Framing "choices": A longitudinal study of occupational aspirations among 13 to 16 year olds. J. Educat. Work, 12: 21-35.

Ganzeboom, H.B.G. and D.J. Treiman, 2003. Three Internationally Standardised Measures for Comparative Research on Occupational Status. In: Advances in Cross-National Comparison: A European Working Book for Demographic and Socio-Economic Variables, Hoffmeyer-Zlotnik, J.H.P. and C. Wolf (Eds.), Springer, Boston, MA ISBN-10: 978-1-4419-9186-7, pp: 159-193.

Gottfredson, L.S., 2002. Gottfredson's Theory of Circumscription, Compromise and Self-Creation. In: Career choice and Development, Brown D. (Ed.), Jossey-Bass, San Francisco.

Goyder, J., N. Guppy and M. Thompson, 2003. The allocation of male and female occupational prestige in an Ontario urban area: A quartercentury replication. Canadian Rev. Soc. Anthropol., 40: 417-439.

Hanson, S.L., 1994. Lost talent: Unrealized educational aspirations and expectations among U.S. youths. Sociol. Educat., 67: 159-183.

Harrell, M.C. and L.L. Miller, 1997. New opportunities for military women: Effects upon readiness, cohesion and morale, (MR-896-OSD). RAND Corporation, Santa Monica, CA.

Hellenga, K., M.S. and J.E. Rhodes, 2002. AfricanAmerican adolescent mothers' vocational aspirationexpectation gap: Individual, social and environmental influences. Psychol. Women Q., 26: 200-212.

Helwig, A.A., 2001. A test of Gottfredson's theory using a ten-year longitudinal study. J. Career Develop. 28: 77-95.

Helwig, A.A., 2008. From childhood to adulthood: A 15year longitudinal career development study. Career Develop. Q., 57: 38-50.
Henderson, S., B. Hesketh and K. Tuffin, 1988. A test of Gottfredson's theory of circumscription. J. Vocat. Behav., 32: 37-48.

Holland, J.L., 1985. Making vocational choices: A Theory of Vocational Personalities and Work Environments. 2nd Edn., Prentice-Hall, Englewood Cliffs, pp: 211.

Hotchkiss, L. and H. Borow, 1996. Sociological Perspectives on Work and Career Development. In: Career Choice and Development Brown, D. and L. Brooks (Eds.), Jossey-Bass, San Francisco, pp: 281-334.

Hunter, M., 2007. Honor betrayed: Sexual abuse in America's military. Barricade Books, Fort Lee, NJ.

Israel, G.D., 1992. Sampling issues: Nonresponse. Gainesville. Cooperative Extension Service, FL: University of Florida.

Jacobs, J.E. and J.S. Eccles, 1992. The influence of parent stereotypes on parent and child ability beliefs in three domains. J. Personality Soc. Psychol., 63: 932-944.

Jacobs, J.E., 1991. The influence of gender stereotypes on parent and child math attitudes: Differences across grade-levels. J. Educat. Psychol., 83: 518-527.

Kenny, J.A., 1967. The child in the military community. J. Child Psychiatry, 6: 51-63.

Kurpius, S.E. and L. Lucart, 2000. Military and civilian undergraduates: Attitudes toward women, masculinity and authoritarianism. Sex Roles, 43: 255-265.

Lammers, W.J. and P. Badia, 2005. Fundamentals of behavioral research. Belmont, CA: Wadsworth.

Lawson, K.M., A.C. Crouter and S.M. McHale, 2015. Links between family gender socialization experiences in childhood and gendered occupational attainment in young adulthood. J. Vocat. Behav., 90: 26-35.

Lent, R.W., S.D. Brown and G. Hackett, 1994. Toward a unifying social cognitive theory of career and academic interest, choice and performance. J. Vocat. Behav., 45, 79-122.

Lent, R.W., S.D. Brown and G. Hackett, 2000. Contextual supports and barriers to career choice: A social cognitive analysis. J. Counsel. Psychol., 47: 36-49. DOI: 10.1037/0022-0167.47.1.36.

Levine, T.R. and C.R. Hullett, 2002. Eta-squared, partial eta-squared and misreporting of effect size in communication research. Human Communi. Res., 28: 612-625.

Marcia, J.E., 1980. Identity in Adolescence. In: Handbook of Adolescent Psychology, Adelson, J. (Ed.), Wiley and Sons, New York.

McCullough, M., D. Ashbridge and R. Pegg, 1994. The effect of self-esteem, family structure, locus of control and career goals on adolescent leadership behavior. Adolescence, 29: 605-611. 
McMahon, M., 2016. Career Counselling: Constructivist Approaches. Routledge.

Mello, Z.R., 2008. Gender variation in developmental trajectories of educational and occupational expectations and attainment from adolescence to adulthood. Develop. Psychol., 44: 1069-1080.

Mendez, L.M.R. and K.M. Crawford, 2002. Gender-role stereotyping and career aspirations: A comparison of gifted early adolescent boys and girls. J. Secondary Gifted Educat., 13: 96-107.

Mickelson, R.A., 2003. Gender, Bourdieu and the anomaly of women's achievement redux. Sociol. Educat., 76: 373-375. DOI: 10.2307/1519873.

Morinaga, Y., I.H. Frieze and A. Ferligoj, 1993. Career plans and gender-role attitudes of college students in the United States, Japan and Slovenia. Sex Roles, 29: 317-334.

Mosher, D.L. and S. Tomkins, 1988. Scripting the macho man: Hypermasculine socialization and enculturation. J. Sex Res., 25: 60-84.

Nakagawa, S. and I.C. Cuthill, 2007. Effect size, confidence interval and statistical significance: A practical guide for biologists. Bio. Rev., 82: 591-605.

Nakao, K. and J. Treas, 1990. Computing 1989 Prestige Scores, GSS Methodological Report No. 70. Chicago: NORC. National Defense Authorization Act, U.S.C.

Nicol, A.A.M., D. Charbonneau and K. Boies, 2007. Right-wing authoritarianism and social dominance orientation in a Canadian military sample. Military Psychol., 19: 239-257.

Nilson, L.B., 1978. The social standing of a housewife. J. Marriage Family, 40: 541-548.

O'Brien, K.M. and R.E. Fassinger, 1993. A causal model of the career orientation and career choice of adolescent women. J. Counsel. Psychol., 40: 456-469.

Parsons, J.E., T.F. Adler and C.M. Kaczala, 1982. Socialization of achievement attitudes and beliefs: Parental influences. Child Develop., 53: 310-321.

Patton, W. and P.A. Creed, 2007. The relationship between career variables and occupational aspirations and expectations for Australian high school adolescents. J. Career Develop., 34: 127-148.

Perry, J.C., J. Przybysz and M. Al-Sheikh, 2009. Reconsidering the "aspiration-expectation gap" and assumed gender differences among urban youth. J. Vocat. Behav., 74: 349-354.

Phipps, B.J., 1995. Career dreams of preadolescent students. J. Career Develop., 22: 19-32.

Pratto, F., J. Sidanius, L.M. Stallworth and B.F. Malle, 1994. Social dominance orientation: A personality variable predicting social and political attitudes. J. Personality Soc. Psychol., 67: 741-763.

DOI: $10.1037 / 0022-3514$.67.4.741
Primé, D.R., L. Nota, L. Ferrari, D.E.P. Schultheiss and S. Soresi et al., 2010. Correspondence of children's anticipated vocations, perceived competencies and interests: Results from an Italian sample. J. Vocat. Behav., 77: 58-62.

Rojewski, J., 1997. Effects of economic disadvantaged status and secondary vocational education on adolescent work experience and postsecondary aspirations. J. Vocat. Techni. Educat., 14: 43-59.

Rojewski, J.W. and B. Yang, 1997. Longitudinal analysis of select influences on the development of occupational aspirations. J. Vocat. Behav., 51: $375-410$.

Roulo, C., 2013. Defense Department expands women's combat role. DoD News.

Schoon, I. and S. Parsons, 2002. Teenage aspirations for future careers and occupational outcomes. J. Vocat. Beha., 60: 263-288.

Schoon, I., P. Martin and A. Ross, 2007. Career transitions in times of social change. J. Vocat. Behav., 70: 78-96.

Shapiro, D. and J. Crowley, 1982. Aspirations and expectations of youth in the United States. Part 2: Employment Activity, Youth Soc., 14: 33-58.

Sidanius, J., 1993. The Psychology of Group Conflict and the Dynamics of Oppression: A Social Dominance Perspective. In: Explorations in Political Psychology, Iyengar, S. and W. McGuire (Eds.), Duke University Press, Durham, NC, pp: 183-219.

Slater, A., E. Halliwell, H. Jarman and E. Gaskin, 2017. More than just child's play? An experimental investigation of the impact of an appearance-focused internet game on body image and career aspirations of young girls. J. Youth Adolescence, 46: 2047-2059.

Sun, Y. and Y. Li, 2008. Stable postdivorce family structures during late adolescence and socioeconomic consequences in adulthood. J. Marriage Family, 70: 129-143.

Swick, A. and E. Moore, 2018. The (Mostly) good news on women in combat. Center for a New American Security.

Teig, S. and J.E. Susskind, 2008. Truck driver or nurse? The impact of gender roles and occupational status on children's occupational preferences. Sex Roles, 58: 848-863. DOI: 10.1007/s11199-008-9410-x

Thompson, B., 1999. Statistical significance test, effect size reporting and the vain pursuit of pseudoobjectivity. Theory Psychol., 9: 191-196.

DOI: $10.1177 / 095935439992007$

Thompson, B., 2007. Effect sizes, confidence intervals and confidence intervals for effect sizes. Psychol. Schools, 44: 423-432. DOI: 10.1002/pits.20234

Trice, A.D. and N. McClellan, 1993. Do children's career aspirations predict adult occupations? An answer from a secondary analysis of a longitudinal study. Psychol. Reports, 72: 368-370. 
Trice, A.D. and T.M. Gilbert, 1990. Locus of control and career aspirations of fourth grade students. Psychol. Reports, 67: 1345-1346.

Trice, A.D., M.A. Hughes, C. Odom, K. Woods and N.C. McClellan, 1995. The origins of children's career aspirations: IV. Testing hypotheses from four theories. Career Develop. Quarterly, 43: 307-322.

Trobaugh, E.M. 2018. Women, regardless: Understanding gender bias in U.S. military integration. Joint Forces Quarterly, 88: 46-53.

Turchik, J.A. and S.M. Wilson, 2010. Sexual assault in the U.S. military: A review of the literature and recommendations for the future. Aggress. Violent Behav., 15: 267-277. DOI: 10.1016/j.avb.2010.01.005

Watanabe, H.K., 1985. A survey of adolescent military family members' self-image. J. Youth Adolescence, 14: 99-107.
Watts, L.L., M.C. Frame, R.G. Moffett, J.L. Van Hein and M. Hein, 2015, Gender, perceived career barriers and aspirations. J. Applied Soc. Psychol., 45: 10-22. DOI: $10.1111 /$ jasp. 12271

Whiston, S.C. and B.K. Keller, 2004. The influences of the family of origin on career development: A review and analysis. Counsel. Psychol., 32: 493-568.

Williams, K.C. and L.L. Mariglia, 2002. Military Brats: Issues and Associations in Adulthood. In: Military Brats and Other Global Nomads, Ender, M.G. (Ed.), Praeger, Westport, CT, pp: 67-82.

Willick, D.H., G. Gehlker and W.A. McFarland, 1975. Social class as a factor affecting judicial disposition: Defendants charged with criminal homosexual acts. Criminology, 13: 57-77.

DOI: 10.1111/j.1745-9125.1975.tb00654.x 